\title{
INCREASE IN THE ATMOSPHERIC PRESSURE MAY HAVE DRIVEN THE TRANSITION FROM THE FIRST REPLICATORS TO THE FIRST CELLULAR ORGANISMS
}

ARMEN Y. MULKIDJANIAN

Osnabrueck University

Presenting Author: amulkid@uni-osnabrueck.de

The abiotic formation of amino acids and nucleotides was shown to be favored by high levels of cyanide/formamide [1-5]. Spontaneous formation of biological macromolecules should have proceeded via condensations only in the absence of water, which has promted suggestions on the origin of life in a kind of "formamide world" [2-5]. Still, the chemical composition of the cytoplasm points to the origin of the first cells in the presence of water. Specifically, building on the measured $\left[\mathrm{K}^{+}\right] /\left[\mathrm{Na}^{+}\right]>1.0$ at vapor-dominated zones of inland geothermal systems, we suggested the emergence of first cells at primordial anoxic geothermal fields where the elementary composition of the condensed water vapor would resemble the internal milieu of modern cells [6].

The boiling temperature of formamide is $200^{\circ} \mathrm{C}$. Therefore, the transient removal of water and establishment of formamide/cyanide based (bio)chemistry was suggested to happen within impact craters $[7,8]$.

Alternatively, however, evaporation of water could be caused by an atmosphere loss after a giant impact. At the low atmospheric pressure, liquid water would be virtually absent being concentrated on the earth poles, and the earth would resemble modern Mars. Unlike water, formamide and its derivates would be present in a liquid state at the sites of geothermal activity. Therefore, geothermal fields all over the primordial earth could have served as cradles of life. It would be discussed in detail how the atmosphere recovery would slowly increase the amount of liquid water on the surface of earth and drive the transition from the first replicators to the first cellular organisms.

\section{References}

1. Schoffstall, A.M. (1976) Orig Life 7, 399-412. 2. Saladino, R . et al. (2001) Bioorg Med Chem 9, 1249-1253. 3. Benner, S. A., Ricardo, A., and Carrigan, M.A. (2004) Curr Opin Chem Biol 8, 672-689. 4. Barks, H.L. et al. (2010) Chembiochem 11, 1240-1243. 5. Patel, B. H. et al. (2015) Nat Chem 7, 301-307. 6. Mulkidjanian, A.Y., Bychkov, A.Y., Dibrova, D.V., Galperin, M.Y., and Koonin, E.V. (2012) Proc Natl Acad Sci USA 109, E821-830. 7. Šponer, J.E. et al. (2016) Chemistry 22, 3572-3586. 8. Sutherland, J.D. (2016) Angew Chem Int Ed Engl 55, 104-121. 